\title{
Impact of Organic Solvents and Environmental Pollutants on the Physiological Function in Petrol Filling Workers
}

\author{
Nazia Uzma, B. M. Khaja Mohinuddin Salar, B. Santhosh Kumar*, Nusrat Aziz, M. Anthony David and V. Devender \\ Reddy
}

Department of Physiology, Deccan College of Medical Sciences, Hyderabad, India - 500058

*Correspondence to Dr. B. Santhosh Kumar. E-mail: santhosh910@rediffmail.com

Received: March 282008 / Accepted: May 032008 / Published: 30 September 2008

\begin{abstract}
Long term exposure to solvents and air pollutants can lead to deleterious effects on respiratory, haematological and thyroid functioning. The aim of this study was to investigate whether chronic exposure to solvents like benzene and pollutants like carbon monoxide in petrol filling workers had adverse effect on blood parameters, thyroid and respiratory functions. The study group consisted of 42 healthy, non-smoker petrol filling workers, aged 20-50 years with work (exposure) duration from 2-15 years while 36 healthy subjects of the same age group served as controls. Physical examination and measurement of pulmonary functions by portable electronic spirometer were performed. Complete blood pictures (CBP) were determined by normal haematology lab procedure and hormones by Chemiluminescence immunoassay (CLIA) light absorption techniques. There was a significant decrease in the lung volumes and capacities; the restrictive pattern was more prevalent in the workers when compared with the control groups. But in the workers exposed for long period (more than 10 years) the restrictive pattern was changed to mixed pattern. A significant increase in haemoglobin $(\mathrm{Hb})$ (>16 mg \%) and red blood cells (RBC) (5.4 million cells $/ \mathrm{mm}^{3}$ ) were observed in workers with longer period of exposure when compared with the control subjects (14.483 $\mathrm{mg} \%$ and 4.83 million cells $/ \mathrm{mm}^{3}$ for $\mathrm{Hb}$ and RBC respectively). White blood cell count except eosinophils and platelets were significantly lower in workers compared to controls. Marked increase in the tetra iodothyroinine (T4), free thyroxine (T4F) level and significant decrease in thyroid stimulating hormones (TSH), and tri-iodothyronine (T3) were observed between long term exposed and non - exposed groups. Till now researchers focused only on the effect of solvents in workers professionally exposed to solvents without considering the effect of concomittant air pollution. The result obtained from present study indicates that there is a significant toxic effect of solvents and air pollutants on workers exposed for longer duration. Improved detection and prevention technologies are needed to answer environmentally related health questions for petrol filling workers.
\end{abstract}

Keywords: benzene, carbon monoxide, pulmonary function, thyroid hormones, complete blood picture

\section{Introduction}

Health effects of occupational exposure to gasoline and air pollution from vehicular sources are relatively unexplored among petrol filling workers. Neglect of ventilation in the work place or failure to use personal protective equipment when using petrol containing solvents like benzene will increase the incidence of toxic effects of benzene in humans, which includes haematotoxicity, immunotoxicity, neurotoxicity and carcinogenicity [1]. Acute poisoning can lead to death with higher exposure associated with inflammation of respiratory tract and haemorrhage in the lungs. Various occupational solvents like benzene and atmospheric polluted air are absorbed into the human body either through the respiratory tract or via epidermal contact. These may cause primary respiratory symptoms and impaired pulmonary and dermatological functions [2].

Air pollutants and chemicals with known adverse effects like Benzene, Lead, other heavy metals, and Carbon monoxide (CO) and their metabolites can cause adverse health effects by interacting with molecules crucial to the biochemical or physiological processes of the human body [3]. All these have been found to lead to deleterious effect 
on respiratory, endocrine and haematopoietic systems. High ambient air concentrations of solvents and pollutants had well defined and marked systemic pulmonary inflammatory response with decreased forced vital capacity(FVC), forced expiratory volume in the first second (FEV1), Inspiratory and expiratory flow rates [4] .

The haematopoietic system, as the cells recycle continually, is highly sensitive to most of the air pollutants, which are reaching the blood very fast without being biotransformed. The solvents and air pollutants may interfere in the process of red blood cells proliferation.these changes are reflected in the synthesis of heme and the life expectancy of RBCs. Toxic material from air leads to significant damage to red blood cells causing aplastic anemia [5]. This would lead to increase erythropoises as compensation. In the endocrine system the thyroid glands are important targets of the solvents and air pollutants especially like Lead [6]. The hormones of the hypothalamic-hypophysial axis are controlled by diverse factors, and constitute the target of toxic substances present in the solvents and air pollutants like heavy Lead [7]. So it is reasonable to suppose that workers exposed to benzene and lead may have altered the values of TSH and presumably thyroid hormones (T3, T4 and T4F).

The main purpose of this study was to examine the evidence for the occurrence of the elevated levels of respiratory, haematological and thyroid functioning in a population of male petrol filling workers occupationally exposed to the solvents in petrol and air pollutants for short and long durations.

\section{Materials and Methods}

The study was approved by the Ethics Committee of our institution, the DCMS \& OHRC, Hyderabad, India. Written informed consent was obtained from each subject prior to the study.

\section{Study Population}

The present study includes a total of 42 healthy nonsmoker males in the age group of 20-50 years working in different petrol pump in the twin cities of Hyderabad for more than one year. The workers selected here were engaged in petrol filling for more than 8 hours per day and were non-smokers. This is to exclude the exacerbating factors of effect of smoking on lung function. 36 healthy male non-smokers, matching socially and economically with the study group and not exposed to any type of solvents or air pollutants were recruited as control subjects. The study group (petrol workers) were divided into four groups (I - IV) according the years of exposure. Each group contains had more than 10 subjects. A detailed questionnaire requesting information on life time occupational and environmental exposure history, medical history and tobacco smoking were collected using a prestructured proforma. A brief physical and general examination was carried out and relevant data (age, sex, height, weight and smoker or non smoker) were collected. Subjects who had a history of asthma or other illness were excluded. $3 \mathrm{ml}$ of blood from each subject was collected for the evaluation of thyroid hormones and other haematological parameters.

\section{Pulmonary Function Test}

The pulmonary function tests were carried out using an electronic computerized portable spirometer (Recorders and Medicare System, Chandigarh, India). The subjects were given proper instructions about the procedure to be performed. They took the spirometric tests in the standing position and a nose clip was applied to them during the entire maneuver. The spirometer was calibrated each day prior to use. The parameters measured by the apparatus were the (a) Forced Vital Capacity (FVC),(b) Forced Expiratory Volume in the first second $\left(\mathrm{FEV}_{1}\right)$,(c) Peak Expiratory Flow Rate (PEFR), (d) Peak Inspiratory Flow Rate (PIFR), (e) Forced Expiratory Flow in 25-75\% ( $\mathrm{FEF}_{25-75}$ ), (f) Forced Expiratory Flow in $50 \%\left(\mathrm{FEF}_{50}\right)$ of vital capacity, (g) Forced Inspiratory Vital Capacity (FIVC), (h) Inspiratory Capacity (IC) , (i) Expiratory Reserve Volume (ERV) and (j) Mid-Expiratory Flow Rate MMEF\%. Respiratory impairment, obstructive, restrictive, mixed and peripheral airway obstruction (PAO) was classified on the basis of following criteria. Restrictive: $\mathrm{FVC}<80 \%$ of predicted or VC $<70 \%$ of predicted. Obstructive: FEV1\% or FEV1/FVC\% and PEFR $<80 \%$ of predicted. Mixed: VC $<70 \%$ of predicted, FVC\% and FEV1\%, MMEF\% or PEFR $<80 \%$ of predicted. PAO, MMEF $<80 \%$ predicted [4].

\section{Measurement of Carbon Monoxide Level}

CO level was measured by non dispersive infrared analyzer measurement of $\mathrm{CO}$ concentration in air is based on the absorption of infrared radiation by the gas in a non dispersive photometer. The sampling plan was done in 10 fuel stations located in the heavy traffic squares and also in residential area one day 3 times sampling and measurement were scheduled at daily times: 6AM-2PM; 2PM-10PM, 10PM - 6AM and CO for $1 \mathrm{hr}$ mean was calculated [8].

\section{Complete Blood Picture (CBP) Analysis}

Blood samples were obtained by venipuncture from subjects and collected in EDTA coated tubes and delivered to the lab within 6hrs after collection. Analysis was done using normal hematological procedures, Haemoglobin by Sahli's method, total leucocyte count and total erythrocyte count were done using hemocytometer, and differential counts were performed using Leishman staining. The procedures of these tests were given elsewhere [9].

Serum Thyroid Hormone Profile by Chemiluminescence Immunoassay (CLIA) 
Venous blood was collected in a tube and after serum was separated, samples were frozen at $-20^{\circ} \mathrm{C}$ until analysis of thyroid hormones. T3, T4, T4F and TSH levels were measured for evaluation of thyroid function using chemiluminescence immunoassay (CLIA, Beckman Coulter Access Immuno Assay system Fullerton, California, USA). The tracer reagents for T3, T4, T4F and TSH, Wash buffer and working signal reagents were procured from PharMingen and processed as per the instructional manual. The microplate wells were formatted for each serum reference control and subjects' specimens were assayed in duplicate. $50 \mu \mathrm{l}$ of the appropriate serum reference control or specimen was taken into the assigned well to which $100 \mu$ l of the trace (T3 or T4 or T4F or TSH) reagent was added. Following which the plates were briefly swirled gently for 20-30 seconds to mix and cover. The reaction mixture was then incubated in room temperature for 45 minutes and the contents of the microplate discarded by decantation or aspiration, washed with $350 \mu$ l of wash buffer. Finally it was resuspended in $100 \mu \mathrm{l}$ of working signal reagent solution and incubated in the dark for 10 minutes in the room temperature. Then the RLUs (Relative Light Units) were read in each well in a microplate luminometer for at least 0.2 seconds /well and the results were compared with the expected values for the T3, T4, T4F and TSH. All assays were performed in duplicate, inter and intra assay variations were noted considering as valid those values that differed by less than $10 \%$ [10].

\section{Statistical Analysis}

All the data was presented as the Mean \pm Standard Deviation for each of the parameter. The two groups were compared by using unpaired 't'test and $p$ value of less than 0.05 was considered significant.

\section{Results}

Prevalence of various lung abnormalities in different exposure groups were compared using Mantel Haenszal procedure for calculating the age weight ratio. The significance is calculated using Mantel Haenszal's chi square test. The mean age of the study group was calculated as $32.31 \pm 8.3$ for control and $21.21 \pm 4.26$, $26.25 \pm 1.5,30.34 \pm 3.4$ and $41.37 \pm 1.41$ for group I - IV respectively. The body mass index (BMI) was calculated in each group using the formula weight $(\mathrm{kg}) /$ height $\left(\mathrm{m}^{2}\right)$ and found to be $21.9 \pm 4.9,18.36 \pm 1.67,19.02 \pm 1.48$, $22.32 \pm 3.6$ and $28.13 \pm 5.4$ for control, group I-IV respectively. Significant increase in the BMI was observed among the petrol filling workers with increase in the years of exposure.

The multiple regression analysis showed that regression coefficient of age were not found to be significant for all lung function parameters, whereas years of exposure showed a significant regression coefficient $(p<0.001)$ for all lung functions. Present study demonstrates altered lung function in petrol-filling workers related to duration of exposure, which is given in Table 1 . When compared to the predicted values there was statically significant decline in the values of VC, FVC, IC and FIVC among petrol filling workers, which denotes prevalence of restrictive type of lung diseases till the exposure period is 10 years. But as the exposure period was increased more than 10 years there was a steady decrease in VC, FVC, FEV1, MMEF and PEFR indicating the restrictive pattern changing to mixed type of lung diseases (Figure 1 and 2). Steady reduction in the midexpiratory flow rate (MMEF) indicates the peripheral airway obstruction (PAO). The figures $1 \& 2$ showed that restrictive/PAO type of respiratory impairment was observed during the early period of exposure (1-5, 5-10 years) which is changed to mixed in other exposure groups (10-15 and $>15$ years).

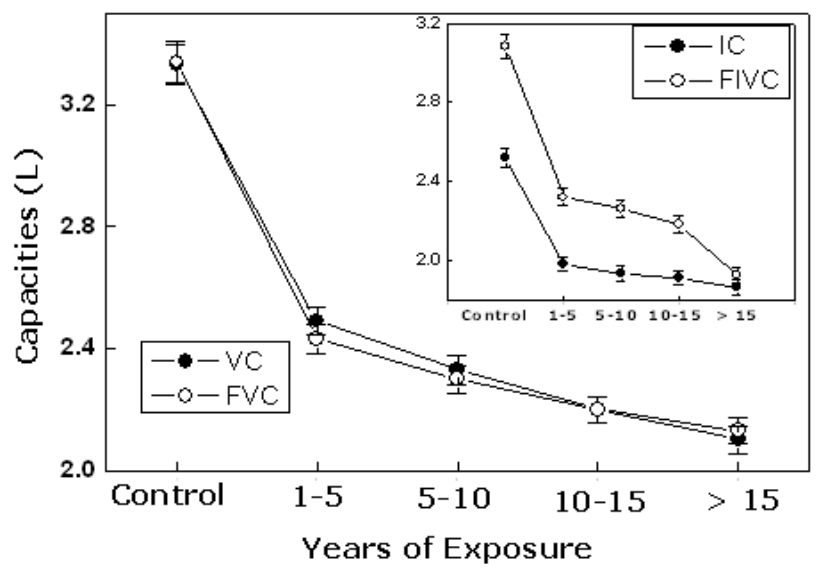

Figure 1: VC / FVC Lung Function and Effect of Exposure; Changes in the vital capacity (VC) and forced vital capacity (FVC) in petrol filling workers with year of exposure. Inset showing the change in inspiratory capacity (IC) and forced inspiratory vital capacity (FIVC) among petrol filling workers exposed to both solvents and polluted air.

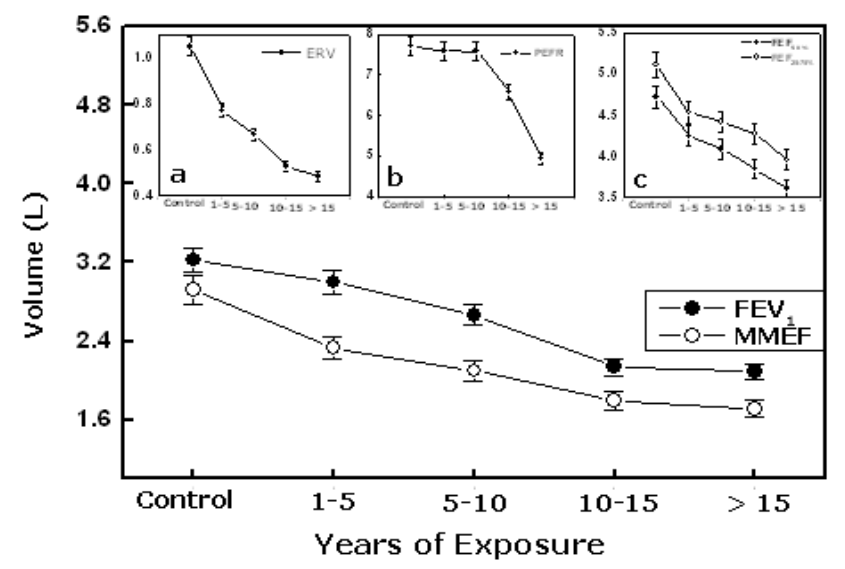

Figure 2: FVC / MMEF and Effect of Exposure; Changes in the forced expiratory volume in first second $\left(\mathrm{FEV}_{1}\right)$ and mid expiratory flow rate (MMEF) in petrol filling workers 
with year of exposure. Inset showing (a) Change in expiratory reserve volume (ERV) (b) Change in peak expiratory flow rate (PEFR) (c) Change in $\mathrm{FEF}_{50 \%}$ and
$\mathrm{FEF}_{25-75 \%}$ among petrol filling workers exposed to both solvents and polluted air.

Table 1: Lung Function Parameters and Effect of Exposure to Petrol and Pollutants

\begin{tabular}{|c|c|c|c|c|c|}
\hline Parameter & $\begin{array}{l}\text { Years of } \\
\text { Exposure }\end{array}$ & Observed & Predicted & Percent predicted (\%) & $P$ value \\
\hline \multirow{4}{*}{ VC } & $1-5$ & $2.29 \pm 0.556$ & \multirow{4}{*}{$3.33 \pm 0.3$} & 68.76 & $0.007^{*}$ \\
\hline & $5-10$ & $2.33 \pm 0.312$ & & 69.9 & $0.034^{*}$ \\
\hline & $10-15$ & $2.2 \pm 0.409$ & & 66.07 & $0.001^{*}$ \\
\hline & $>15$ & $2.23 \pm 0.200$ & & 66.96 & $0.022^{*}$ \\
\hline \multirow{4}{*}{ FVC } & $1-5$ & $2.3 \pm 0.556$ & \multirow{4}{*}{$3.34 \pm 0.281$} & 68.86 & $0.007^{*}$ \\
\hline & $5-10$ & $2.37 \pm 0.312$ & & 68.86 & $0.031^{*}$ \\
\hline & $10-15$ & $2.2 \pm 0.409$ & & 65.85 & $0.001^{*}$ \\
\hline & $>15$ & $2.13 \pm 0.200$ & & 63.77 & $0.02^{*}$ \\
\hline \multirow{4}{*}{ FEV1 } & $1-5$ & $3.1 \pm 0.551$ & \multirow{4}{*}{$3.228 \pm 0.707$} & 96.27 & $0.625^{\mathrm{NS}}$ \\
\hline & $5-10$ & $2.67 \pm 0.62$ & & 82.91 & $0.487^{\mathrm{NS}}$ \\
\hline & $10-15$ & $2.14 \pm 0.764$ & & 66.45 & $0.744^{\mathrm{NS}}$ \\
\hline & $>15$ & $2.09 \pm 0.194$ & & 64.9 & $0.014^{*}$ \\
\hline \multirow{4}{*}{ MMEF } & $1-5$ & $2.43 \pm 0.43$ & \multirow{4}{*}{$2.92 \pm 0.52$} & 83.21 & $0.086^{\mathrm{NS}}$ \\
\hline & $5-10$ & $2.1 \pm 0.61$ & & 71.9 & $0.023^{*}$ \\
\hline & $10-15$ & $1.8 \pm 0.36$ & & 61.64 & $0.001^{*}$ \\
\hline & $>15$ & $1.71 \pm 0.54$ & & 58.56 & $0.000^{*}$ \\
\hline \multirow{4}{*}{ PEFR } & $1-5$ & $7.6 \pm 2.44$ & \multirow{4}{*}{$7.73 \pm 2.11$} & 98.31 & $0.778^{\mathrm{NS}}$ \\
\hline & $5-10$ & $7.58 \pm 2.34$ & & 98.05 & $0.716^{\mathrm{NS}}$ \\
\hline & $10-15$ & $6.58 \pm 2.28$ & & 85.12 & $0.164^{\mathrm{NS}}$ \\
\hline & $>15$ & $4.93 \pm 1.93$ & & 63.77 & $0.043^{*}$ \\
\hline \multirow{4}{*}{$\mathrm{FEF}_{25-75}$} & $1-5$ & $4.25 \pm 1.45$ & \multirow{4}{*}{$4.72 \pm 1.105$} & 90.04 & $0.335^{\mathrm{NS}}$ \\
\hline & $5-10$ & $4.09 \pm 0.81$ & & 86.65 & $0.610^{\mathrm{NS}}$ \\
\hline & $10-15$ & $3.85 \pm 2.33$ & & 81.56 & $0.004^{*}$ \\
\hline & $>15$ & $3.61 \pm 0.863$ & & 76.48 & $0.000^{*}$ \\
\hline \multirow{4}{*}{$\mathrm{FEF}_{50}$} & $1-5$ & $4.53 \pm 1.53$ & \multirow{4}{*}{$5.12 \pm 0.48$} & 88.47 & $0.543^{\mathrm{NS}}$ \\
\hline & $5-10$ & $4.42 \pm 0.912$ & & 86.32 & $0.612^{\mathrm{NS}}$ \\
\hline & $10-15$ & $4.28 \pm 0.561$ & & 83.59 & $0.217^{\mathrm{NS}}$ \\
\hline & $>15$ & $3.96 \pm 1.072$ & & 77.34 & $0.056^{\mathrm{NS}}$ \\
\hline \multirow{4}{*}{ ERV } & $1-5$ & $0.77 \pm 0.712$ & \multirow{4}{*}{$1.047 \pm 0.734$} & 82.91 & $0.063^{\mathrm{NS}}$ \\
\hline & $5-10$ & $0.664 \pm 0.456$ & & 63.41 & $0.049^{*}$ \\
\hline & $10-15$ & $0.528 \pm 0.472$ & & 50.42 & $0.001^{*}$ \\
\hline & $>15$ & $0.486 \pm 0.234$ & & 46.41 & $0.000^{*}$ \\
\hline \multirow{4}{*}{ IC } & $1-5$ & $1.935 \pm 0.328$ & \multirow{4}{*}{$2.516 \pm 1.178$} & 76.9 & $0.041^{*}$ \\
\hline & $5-10$ & $1.933 \pm 0.212$ & & 76.82 & $0.043^{*}$ \\
\hline & $10-15$ & 1.909 \pm 0.581 & & 75.87 & $0.027^{*}$ \\
\hline & $>15$ & $1.861 \pm 0.269$ & & 73.96 & $0.009^{*}$ \\
\hline \multirow{4}{*}{ FIVC } & $1-5$ & $2.231 \pm 0.544$ & \multirow{4}{*}{$3.083 \pm 0.2877$} & 72.36 & $0.048^{*}$ \\
\hline & $5-10$ & $2.261 \pm 0.643$ & & 73.33 & $0.053^{\mathrm{NS}}$ \\
\hline & $10-15$ & $2.183 \pm 0.841$ & & 70.8 & $0.011^{*}$ \\
\hline & $>15$ & $1.924 \pm 0.293$ & & 62.4 & $0.032^{*}$ \\
\hline
\end{tabular}

${ }^{\text {NS- }}{ }^{-}$nonsignificant, ${ }^{*}$-Significant 
Figure 3 shows the $\mathrm{CO}$ level at residential, petrol filling stations and traffic areas. The CO level in the residential area was found to be minimum in each sampling measurements. The maximum CO level found in the traffic and petrol filling stations in between 6AM 2PM $\left(4300 \pm 412 \mu \mathrm{g} / \mathrm{m}^{3}\right.$ and $3394 \pm 484 \mu \mathrm{g} / \mathrm{m}^{3}$ respectively) and the minimum was in between 10PM -6AM $(310 \pm 116$ $\mu \mathrm{g} / \mathrm{m} 3$ and $292 \pm 104 \mu \mathrm{g} / \mathrm{m} 3$ respectively).

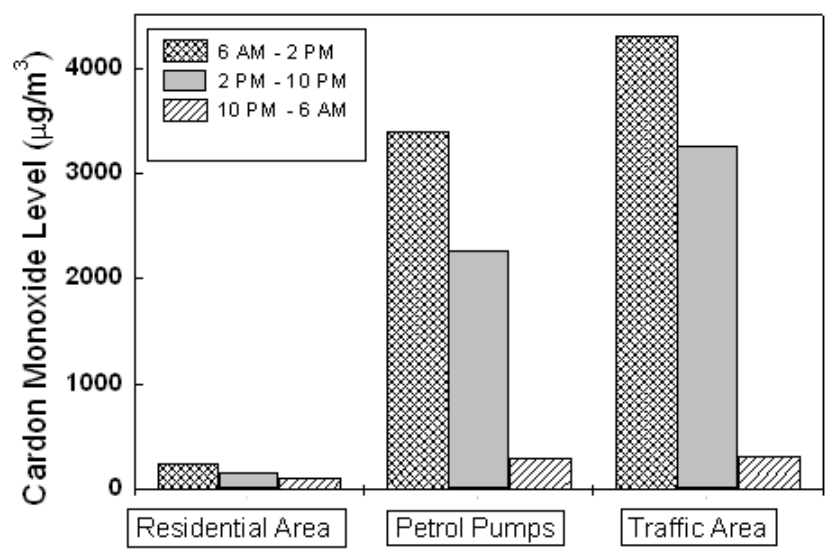

Figure 3: Carbon monoxide levels at different time in residential area, petrol filling station and traffic areas.

Table 2 represents the concentration of $\mathrm{Hb}, \mathrm{RBC}$ and effects of solvents and pollutant air. During the early period of exposure (1-5 years \& 5-10), the average $\mathrm{Hb}$ concentrations was unchanged while comparing with the controls .But as the year of exposure increases more than 10 years there was statically significant increase $(p<0.05)$ in the concentration of $\mathrm{Hb}$ and RBC count given in Fig 4.

Table 2: Hematological Parameters and Effect of Exposure to Petrol and Pollutants

\begin{tabular}{|c|c|c|c|c|}
\hline Parameter & $\begin{array}{l}\text { Years of } \\
\text { Exposure }\end{array}$ & $\begin{array}{l}\text { Count in } \\
\text { subjects }\end{array}$ & $\begin{array}{c}\text { Count in } \\
\text { control }\end{array}$ & $p$ value \\
\hline \multirow{4}{*}{$\begin{array}{l}\mathrm{Hb} \\
\text { (g/dl) }\end{array}$} & $1-5$ & $14.537 \pm 0.8501$ & & $0.631^{\mathrm{NS}}$ \\
\hline & $5-10$ & $14.56 \pm 0.8912$ & \multirow{3}{*}{$14.483 \pm 0.828$} & $0.224^{\mathrm{NS}}$ \\
\hline & $10-15$ & $16.16 \pm 1.15$ & & $0.005^{*}$ \\
\hline & $>15$ & $16.08 \pm 1.92$ & & $0.015^{*}$ \\
\hline \multirow{4}{*}{$\begin{array}{l}\text { RBC } \\
\text { (million } \\
\text { cells/mm } / \mathrm{mm}^{3} \text { ) }\end{array}$} & $1-5$ & $5.103 \pm 0.400$ & \multirow{4}{*}{$4.836 \pm 0.254$} & $0.220^{\mathrm{NS}}$ \\
\hline & $5-10$ & $5.403 \pm 0.166$ & & $0.443^{\mathrm{NS}}$ \\
\hline & $10-15$ & $5.373 \pm 1.15$ & & $0.004^{*}$ \\
\hline & $>15$ & $5.408 \pm 0.489$ & & $0.027^{*}$ \\
\hline \multirow{4}{*}{$\begin{array}{l}\text { Platelets } \\
\text { (Lakhs } \\
\text { cells/mm³) }\end{array}$} & $1-5$ & $2.85 \pm 0.46$ & \multirow{4}{*}{$3.36 \pm 0.208$} & $0.098^{\mathrm{NS}}$ \\
\hline & $5-10$ & $3.2 \pm 0.16$ & & $0.785^{\mathrm{NS}}$ \\
\hline & $10-15$ & $2.46 \pm 0.44$ & & $0.009^{*}$ \\
\hline & $>15$ & $2.48 \pm 0.44$ & & $0.012^{*}$ \\
\hline
\end{tabular}

NS- nonsignificant, ${ }^{\text {*- }}$ Significant

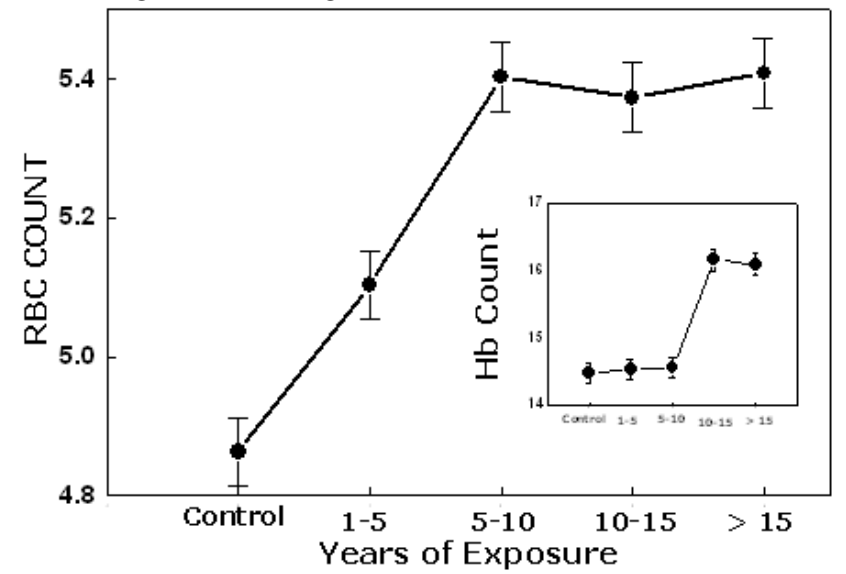

Figure 4: RBC Count and Effect of Exposure; Changes in the red blood cell (RBC) count petrol filling workers with year of exposure. Inset shows the change in haemoglobin (Hb) count among petrol filling workers exposed to both solvents and polluted air.

Figure 5 shows the relationship between differential leukocyte count and effect of exposure. All types of white blood cells (WBCs) measured were significantly decreased $(p<0.05)$ in workers with more than ten years of exposure. But there was a significant increase only in the Eosinophils count in workers with increase in years of exposure. In control group the platelet count was observed in the higher normal range but a statistical significant decrease was observed in workers with more than 10 years of exposure (Figure 6). All these results are pointing towards the fact that solvents and pollutant from the petrol and air have an adverse effect on the hematological functioning with a longer period of exposure.

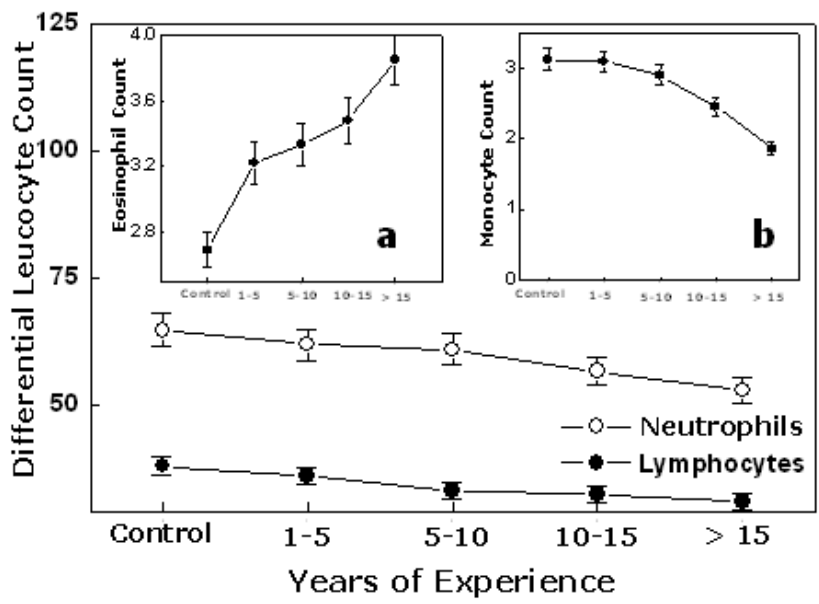

Figure 5: Neutrophil, lymphocyte count and effect of exposure; Changes in the neutrophil and lymphocyte count in petrol filling workers with year of exposure. Inset showing (a) Increase in the eosinophil count with year of exposure to both solvents and polluted air; and (b) 
decrease in the monocyte count among petrol filling workers exposed to both solvents and polluted air.

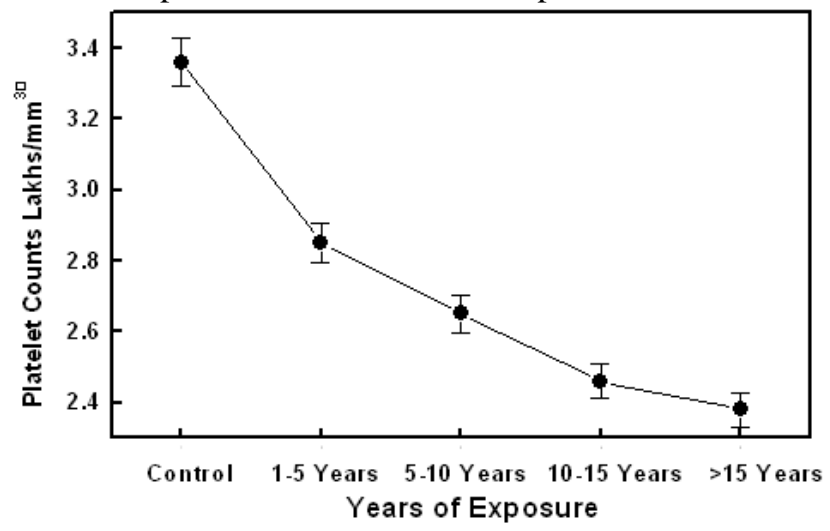

Figure 6: Effect of Exposure on platelet count; showing a decrease in the platelet count as the time of exposure increases.

The table 3 gives the values of thyroid hormones, TSH and effect of exposure. The data obtained from the four study group were in the reference range values, but it is noticeable that $\mathrm{T} 4$ and $\mathrm{T} 4 \mathrm{~F}$ were near the upper limit and were statistically different from unexposed control group $(\mathrm{p}<0.05)$. There was significant correlation between the year of exposure to solvents and polluted air and the hormonal level. From the figure 7 it is very much clear that there is a decrease in the T3 and TSH levels when compared with the control subjects and their level were further decreased as the years of exposure are increased and is statistically significant $(\mathrm{p}<0.001)$.

Table 3: Thyroid function: Effect of Exposure to Petrol and Pollutants

\begin{tabular}{cccc}
\hline Parameter & $\begin{array}{c}\text { Years of } \\
\text { Exposure }\end{array}$ & $\begin{array}{c}\text { Count in } \\
\text { subjects }\end{array}$ & $\begin{array}{r}\text { Count in } \\
\text { control }\end{array}$ \\
\hline & $1-5$ & $121.3 \pm 22.3$ & \\
$\mathrm{~T} 3$ & $5-10$ & $110 . \pm 15.6$ & \\
$(\mathrm{ng} / \mathrm{dl})$ & $10-15$ & $100 . \pm 20.1$ & $134.4 \pm 18.6$ \\
& $>15$ & $101 . \pm 18.1$ & \\
& $1-5$ & $8.52 \pm 0.81$ & \\
$\mathrm{~T} 4$ & $5-10$ & $9.27 \pm 1.1$ & \\
$(\mu \mathrm{g} / \mathrm{dl})$ & $10-15$ & $9.20 \pm 1$ & $6.6 \pm 6.6$ \\
& $>15$ & $9.6 \pm 1.4$ & \\
& $1-5$ & $1.4 \pm 0.2$ & \\
$\mathrm{~T} 4 \mathrm{~F}$ & $5-10$ & $1.5 \pm 0.5$ & \\
$(\mathrm{ng} / \mathrm{dl})$ & $10-15$ & $1.4 \pm 0.4$ & $1.3 \pm 0.4$ \\
& $>15$ & $1.5 \pm 0.4$ & \\
$\mathrm{TSH}$ & $1-5$ & $1.69 \pm 0.63$ & \\
$(\mu \mathrm{lU} / \mathrm{ml})$ & $5-10$ & $1.39 \pm 0.5$ & $1.8 \pm 0.5$ \\
\hline
\end{tabular}

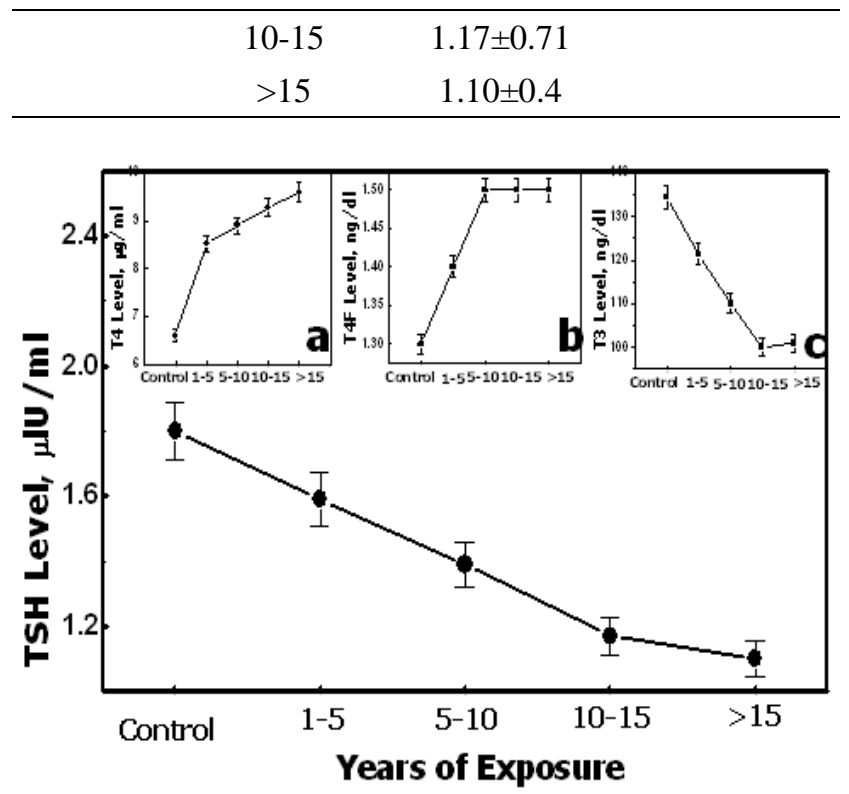

Figure 7: TSH, Thyroid hormones and effect of exposure; Effect of Exposure on Thyroid Hormones levels; showing a decrease in the thyroid stimulating hormone (TSH) level as the exposure time increases. Inset shows: (a) an Increase in the T4 level with the increase in exposure time; (b) an initial increase in the T4F level till 10 years of exposure, followed by a constant level of T4F; and (c) a constant decrease in the levels of $\mathrm{T} 3$ as the years of exposure increase.

\section{Discussion}

Several studies are available regarding the work exposure of petroleum products, showing the decline in VC, FVC, FIVC and IC. The studies conducted by Zuskin et al [11], Lee et al [12] found that the exposure to solvents at work place had significantly more respiratory symptoms than control group. Another study conducted by Paggiaro et al [13] showed that occupational exposure to organic solvents might cause chronic air way impairment with non specific bronchial hyper responsiveness in shoe factory workers. Kesavachandran et al [4] found that high prevalence of respiratory symptoms was primarily a consequence of exposure to the petrol vapors found in the work place in the petrol filling stations. But the present study indicates the exposure to solvents and air pollutants leads to restrictive type of lung disease among them but with chronic exposure (more than 10 years) the restrictive pattern was changed to mixed pattern of lung disease. The particles generated from petrol exhaust are extremely small and are present in the nuclei or accumulation modes, with diameters of $0.02 \mathrm{~nm}$ and $0.2 \mathrm{~nm}$ respectively and as the surface area is large they can carry much larger fraction of toxic compounds, such as hydrocarbons and metals on their surface. They can remain airborne for longer period and deposit in greater numbers and deeper into the smaller airways and the lungs than large sized 
particles [14]. Hence chronic exposure to them can lead to chronic inflammation of respiratory tract including smaller airways and lung parenchyma, hence the restrictive pattern changes into a mixed pattern of lung disease.

Most of the petrol filling stations were situated near to the heavy traffic; the workers were more prone to exposure to $\mathrm{CO}$. The ambient air concentration of $\mathrm{CO}$ was maximum during the peak working hours (6AM - 2PM), the workers were exposed to more amount of $\mathrm{CO}$ along with other air pollutant and solvents.

Previous studies conducted by Qing Lan et al [15] showed that exposure to solvents like benzene decreases the RBC count and $\mathrm{Hb}$ level causing anemia among workers exposed to $>10 \mathrm{ppm}$. But the study conducted by us indicates on the contrary that there is a gradual increase the RBC count and $\mathrm{Hb}$ level among the workers exposed to benzene as well as air pollutants like CO. This is supported the study conducted by Erslev et al [16]. They showed that exposure to $\mathrm{CO}$ is causing tissue hypoxia and a stimulation of RBC formation. The CO emitted mainly by internal combustion engines of motor vehicles readily enters the blood through the respiratory system and binds over 200 times more firmly to Hb than oxygen, forming carboxy haemoglobin and seriously interfering with blood's oxygen transport capability, which ultimately leads to hypoxic hypoxia. Tissue hypoxia is the most potent stimulus for the erythropoises so it leads to the stimulation of erythropoietin - a factor which stimulates the erythropoiesis- which ultimately leads to the production of more number of $\mathrm{RBC}$ and $\mathrm{Hb}$ in the circulating blood.

Occupational exposure decreased WBCs and Platelets in petrochemical workers exposed to $<10 \mathrm{ppm}$ benzene. Collins et al and Tsai et al did not detect decreased blood cell counts on routine monitoring of workers exposed to low level of benzene [17-19]. The present study indicates that total WBC, differential counts and platelets were decreased in workers with longer periods of exposure. The studies conducted by Qing Lanet al [15] showed that solvents are causing toxicity to progenitor cells of WBCs and platelets instead of the circulating cells. This may be the reason why there is a decrease in the WBCs and platelet count. T means that CFU (colony forming unit myeloid and lympoid) of the workers with longer period of exposure are very much susceptible to the solvents especially benzene.

There is an initial increase in the Eosinophil counts were observed in workers with less than ten years of exposure, which may be due to the effect of polluted air. Previous studies are indicating towards the point that there are the chances for Eosinophilia among the peoples who are exposed to polluted air [20].

Measurement of the serum concentration of the thyrotrophin (TSH), secreted from the anterior pituitary is generally regarded as the most sensitive indicator for the diagnosis thyroid functions. It was found that there was a significant decrease in the TSH and T3 levels but the T4F and $\mathrm{T} 4$ levels were increasing within the normal ranges.
The decrease in the TSH level could be either due to the toxic effect of the solvents like benzene present in the petrol vapor and polluted air. We believe that the low level of TSH is probably associated with central pituitary dysfunction due to solvent and polluted air exposure [21]. The increase in the T4F and T4 may be due to the fact that when a person is exposed to the environmental pollutants may lead to negative effect on selenium metabolism [22] .Even if the selenium is sufficient, it will be replaced by the solvents present in the petrol vapor or polluted air. This may be the reason for decrease in the T3 and T4F levels. The studies conducted by Goldman and Dillon showed that selenium supplementation does protect against the toxic effect of the environmental pollutant on thyroid function [23]. So in the present study, there was low level of TSH pointing towards the fact that there may be an existence of primary and secondary hypothyroidism. At same time it is clear that some of the solvents and pollutant like lead can accumulate in many organs including the thyroid gland and exert a toxic effect by causing damage directly on the target organ or depressing their functioning.

\section{Conclusion}

This study demonstrated that certain physiological dysfunctioning effects are constantly observed in the occupationally exposed petrol workers. The data suggests that background benzene and air pollutants could account for substantial part of respiratory, hematological and thyroid dysfunctioning. In order to prevent these among petrol filling workers, we suggest that medical observation, including pre employment and periodic medical Checkups, should be performed which include pulmonary function tests. Control strategies should to adopt to reduce the benzene concentration in the ambient air and evaporation control. Thus medical screening and screening of benzene and $\mathrm{CO}$ in air may protect workers from developing chronic respiratory disorders. Early recognition and possibly the removal of sensitive workers from the working place before chronic impairment develops will help. Considerably improved awareness of the sources of toxins in the community would help individuals avoid them. The development of appropriate equipment for monitoring and testing for environmental elements in the community and in workers would be beneficial. Researcher's effort should be increased to identify genetic and other factors that predispose workers to environmental agents and to assess the health impacts among them. Further longer term perspective studies of petrol workers help us get a more comprehensive picture of long term effects of more of these pollutants as the present study would serve as a bench mark.

Acknowledgement: We thank Dr. Santosh K. Tiwari and Dr. Manoj, Centre for Liver Research and Diagnostics, Hyderabad for their help rendered at different occasions. 
The authors are also thankful to Mr. Naser Khan, Lab Technician for his help in the project.

\section{References}

1. Aksoy, M.: Hematotoxicity and carcinogenicity of benzene. Environ. Health Perspect. 1989, 82,193-197.

2. Shouren Kaung; Weihui Liang. Clinical analysis of 43 cases of chronic benzene poisoning, ChemicoBiological Interactions. 2005, 153-154

3. Badman, D. G.; Jaffe, E. R.: Blood and air pollution: State and knowledge and research need. otoloryngology, Head and Neck Surg. 1996, 114, 205-208

4. Kesavachandran, C.; Mathur, N.; Anand, M.; Dhawan, A.: Lung function abnormalities among petrol pump workers of lucknow, north India. Current Science. 2006, 90, 1177-1178.

5. Sadicova, S. S.; Bunglanov, A. A.; Tadzhieva, Z. A.: Indicators of iron metabolism and cellular immunity in healthy children and in those with iron deficiency anemia in relation to ecological conditions.Pediatria 1990, 8, 41-44.

6. Moore, M. R.; McIntosh, M. J.; Bushnell, I. W. R.: The neurotoxicology of head. Neurotoxicology, 1986, 7, 541-556.

7. Lopez, C. M.: Thyroid hormone changes in males exposed to lead in the buenos aires area (Argentina). Pharmcol. Res., 2000, 42(6), 599-602.

8. Malakootain, M.; Yaghmaeian, K.: Investigation of carbon monoxide in heavy traffic intersections of municipal districts. Environ. Sci. Tech. 2004, 1(3), 227-231.

9. Pal, G. K.; Pal, P.: Text book of Practical Physiology, $2^{\text {nd }}$ Edn, Orient Longman: India, 2001, pp-26-92.

10. Hopton, M. R.; Harrap, J. J.: Immunoradiometric assay of thyrotropin as a first line thyroid function test in routine laboratory. Clinical Chemistry. 1986, 32, 691-698.

11. Zuskin, E.; Musajbegovic, J.; Schachter, E. N.; DokoJelini, J.; Bradic: Respiratory function in shoe manufacturing workers. Amj. Ind. Med, 1997, 31(1), 50-55.

12. Lee, B. W.; Kelsey, K. T.; Hashimoto, D.; Yakes, B.; Seitz, T.; Cheristiari, D. C.: The prevalence of primary and upper press room workers exposed to solvents. Occup. Environ. Med. 1997, 39(10), 960-969.

13. Paggiaro, P.; Lastrucci, C.; Di Pede; Bacci, E.; Rossio; Talini, D.: Respiratory pathology caused by exposure to solvents in shoe industry, description of 3 clinical cases. Ital Med. Lav. 1985, 7(4), 149-152.
14. Levsen, K.: The analysis of diesel particulate. Fresenius Z Anal Chem. 1988, 331, 467-478.

15. Qing, Lan; Luoping, Zharg; Guilar, Li; Rappaport, S. M.; Min Sher; Alter, B. P.; Yongi Wo; William Kopp; Suranya Waidyanatha; Charles Rabkin; Weitong Guo: Hematotoxicity in workers exposed to low levels of benzene. Science. 2004, 306, 1774-1776.

16. Williams, W. J.; Beuteler, E.; Erslev, A. J. Haematology.4edn, MacGraw Hill: New York. 1990, 715-717.

17. Qu, Q. S.; Shore, R.; Li, G.; Jin, X.; Chen, L. C.; Cohen, B.; Melikian, A. A.; Eastmond, D.; Rappaport, S. M.; Yin, S.; Li, H.; Waidyanatha, S.; Li, Y.; Mu, R.; Zhang, X.; Li, K.: Haematological changes among chinese workers with a broad range of benzene exposures. Am. J. Ind. Med. 2002, 42, 275285.

18. Collins, J. J.; Belinda, K.; Paul, A.; Nair, M. S.; Rashmi, S.; Braun, J.: Evaluation of Lymphopenia among workers with low-level benzene exposure and the utility of routine data collection. J.Occup. Envirn. Med. 1997, 39(3), 232-237.

19. Tsai, S. P.; Fox, E. E.; Ransdell. J. D.; Wendt, J. K.; Waddell, L. C.; Donnelly, R. P.: A hematology survillance study of petrol chemical workers exposed to benzene. Regul. Toxicol. Pharmacol. 2004, 40, 6773.

20. Moller, G. M.; Overbeek, S. E.; Mecuwsen, V. H.; Hoogesteden, H. C.; Bogard, J. M.: Eosinophils in broncial mucosa in relation to Metacholine dose response curve in atopic astma. J. Appl. Physiol. 1996, 86, 1352-1356.

21. Gustafson, A.; Herdner, P.; Suchutz, A.; Skerfving, S.; Occupational lead exposure and pituitary function. Int. Arch. Occup. Environ. Health. 1989, 61, 277-281.

22. Dundar, B.; Farul Okten; Arslan, M. K.; Nanik Delibas; Bahallin Baykal; Cargalny Arslas; Mustafa Gultepe; Ishan, E. I.: The effect of long term low-dose lead exposure on thyroid function in adolescents. Environmental Research. 2006, 101, 140-145.

23. Goldman, M.; Dillon, R. D.: Interaction of selenium and lead on several aspects of thyroid function in perkin ducklings. Res. Commun. Chem. Pathol. Pharmacol. 1982, 37, 487-490. 